\title{
ARTICLE Induction of autophagy by sphingosine kinase 1 inhibitor PF-543 in head and neck squamous cell carcinoma cells
}

\author{
Masakazu Hamada, Hiroyasu Kameyama, Soichi Iwai and Yoshiaki Yura
}

Sphingosine kinase 1 (SphK1) overexpressed in head and neck squamous cell carcinoma (SCC) regulates tumor growth. The effects of PF-543, a specific SphK1 inhibitor, on human SCC cells were examined. The proportion of viable cells after PF-543 treatment decreased in a time- and dose-dependent manner, and cell death occurred in SphK1-expressing SCC cells. Flow cytometry analysis revealed that PF-543 induced both necrosis and apoptosis. PF-543 also induced granular accumulation of LC3 and conversion from LC3-I to LC3-II, which was blocked by autophagy inhibitors, wortmannin, 3-methyladenine (3-MA), and bafilomycin A1. Treatment of head and neck SCC cells with autophagy inhibitors and PF-543 increased the proportion of cells with necrosis and apoptosis, indicating that autophagy acts to promote cell survival. Reactive oxygen species (ROS) scavenger reduced the cytotoxicity of PF-543. These results demonstrated that PF-543 induces apoptosis, necrosis, and autophagy in human head and neck SCC cells, and that autophagy antagonizes either necrosis or apoptosis.

Cell Death Discovery (2017) 3, 17047; doi:10.1038/cddiscovery.2017.47; published online 14 August 2017

\section{INTRODUCTION}

Sphingolipids, especially ceramide, sphingosine, and sphingosine1-phosphate (S1P) have an important role as regulatory molecules of cancer development. Although S1P promotes cell proliferation and survival, and regulates angiogenesis, sphingosine and ceramide inhibit cell proliferation and stimulate apoptosis. The S1P product is important in the regulation of a variety of biological processes, including $\mathrm{Ca}^{2+}$ mobilization, cytoskeleton rearrangement, cell proliferation, differentiation, survival and motility through activity as an intracellular second messenger and an extracellular ligand for $G$ protein coupled receptors. ${ }^{1-3}$

S1P is formed through phosphorylation of sphingosine in intracellular compartments by sphingosine kinases (SphKs). ${ }^{3-5}$ In human cells, two isozymes, SphK1 and SphK2, are known. SphK1 has been found to be overexpressed in many types of human cancers including prostate cancer, gastric cancer, breast cancer, lung cancer, glioma, Hodgkin's lymphoma, and head and neck $\mathrm{SCC}^{3-5}$ It is involved in tumor progression, invasion, metastasis, and radiation and chemoresistance. ${ }^{3-5}$ In head and neck SCC, elevated SphK1 levels are associated with poor outcomes and a reduction in SphK1 levels is associated with increased patient survival. $^{3}$ Therefore, SphK1 is believed to be a promising target for cancer and inflammatory diseases.

The first known SphK inhibitors were N, N-dimethyl-D-erythrosphingosine (DMS) and L-threo-dihydro-sphingosine (safingol). ${ }^{6-9}$ DMS inhibits both SphK1 and SphK2 by competing with natural substrates. Safingol is a saturated analog of sphingosine and is a protein kinase C (PKC) inhibitor with SphK inhibitory properties. ${ }^{10}$ In combination with cisplatin, safingol has been successfully tested in phase I clinical trials of advanced solid tumors. ${ }^{6}$ Another compound, 2-(p-hydroxyanilino)-4-(p-chlorophenyl) thiazole (SKI-II), is widely used as a SphK1 and SphK2 inhibitor. ${ }^{11}$ The sphingosine analog FTY 720 is a drug that demonstrates great potential for kidney transplantation and the management of chronic autoimmune diseases such as multiple sclerosis. FTY 720 is phosphorylated by SphK1 and the phosphorylated compound is a potent agonist of all S1P receptors (S1PR) except S1P2. ${ }^{12}$ (R)-[1-(4\{[3-methyl-5-(phenylsulfonylmethyl) phenoxy] methyl\} benzyl) pyrrolidin-2-yl] methanol (PF-543) is a novel SphK1 inhibitor reported in 2012 and has 100-fold greater selectivity for SphK1 compared with SphK2. ${ }^{13}$

Autophagy is a catabolic process in which cytoplasmic components are sequestered in membrane-enclosed autophagosomes and delivered to lysosomes for degradation. Autophagy begins with the isolation of a double membrane bound structure. These membrane structures are elongated and microtubuleassociated protein 1 light chain 3 (LC3) is recruited to the membrane. ${ }^{14-16}$ Elongated double membrane forms autophagosomes and sequester cytoplasmic proteins and organelles. After that, the autophagosomes mature, fuse with lysosomes, and become autolysosomes. Subsequently, the isolated contents are digested with lysosomal hydrolase and recycled. Decomposition by autophagy is generally thought to be a cytoprotective mechanism that maintains homeostasis in case of nutrient deficiency or exposure to environmental stress such as hypoxia. Paradoxically, several studies have shown that induction of autophagy can also contribute to caspase-dependent or independent programmed cell death. ${ }^{17,18}$

A number of anti-neoplastic therapies, including radiation therapy, chemotherapy, histone deacetylase inhibitors, arsenic trioxide, TNF- $a$, IFN- $\gamma$, imatinib and rapamycin, have been demonstrated to reduce autophagy as a protective or prosurvival mechanism in human cancer cell lines. Indeed, if autophagy is inhibited, the therapeutic effects of these drugs can be enhanced. ${ }^{17}$ Recent studies reported that the novel SphK1 inhibitor PF-543 exhibited potent anti-proliferative and cytotoxic effects on human colorectal cancer cells. ${ }^{19}$ It mainly induced programmed necrosis, but did not induce apoptosis. However, the 
involvement of autophagy in PF-543-induced cell death remains unclear. In the present study, we examined PF-543-induced autophagy in human head and neck SCC cells, and the role in several cell death mechanisms using autophagy inhibitors.

\section{RESULTS}

Expression of SphK1 in head and neck SCC cells

To determine the expression of SphK1, head and neck SCC cell lines, Ca9-22, HSC-3 and SAS cells were subjected to immunoblotting using antibodies against SphK1. Immunoblot analysis revealed that expression of SphK1 protein was observed in all SCC cells at different levels (Figure 1a). Expression of SphK1 in SAS cells was lower compared with other cell lines.

Inhibition of cell survival by PF-543

The effects of PF-543 on SCC cell viability were examined by MTT assay. In this study, Ca9-22 and HSC-3 cells with clearly detected SphK1 were used, and cells were cultured in the presence of PF-543 at concentrations of $1,5,10,25$ or $50 \mu \mathrm{M}$ for 24,48 and $72 \mathrm{~h}$. As a result, PF-543 dose- and time-dependently inhibited cell proliferation and the cell viability of Ca9-22 cells treated with $25 \mu \mathrm{M}$ PF-543 was $19.8 \%$ of the untreated control (Figure $1 \mathrm{~b}$ ). When HSC-3 cells were treated with $25 \mu \mathrm{M}$ PF-543 for $72 \mathrm{~h}$, the proportion of viable cells decreased to $26.7 \%$ of the control (Figure 1b). The morphology of these SCC cells was affected by $25 \mu \mathrm{M}$ PF-543. The cells rounded and bound to adjacent cells in a fine intercellular cell process in $24 \mathrm{~h}$. This morphological change was maintained at $72 \mathrm{~h}$ (Figure 1c).

\section{Cell death induction by PF-543}

Ca9-22 and HSC-3 cells were treated with $25 \mu \mathrm{M}$ PF-543 for $72 \mathrm{~h}$, stained with annexin $\mathrm{V}$-conjugated to fluorescein isothiocyanate (FITC-annexin V) and propidium iodide (PI), and subjected to flow cytometry (Figure 2a). The cell population was classified into 4 types, Annexin V-negative and Pl-negative viable cells, Annexin V-positive and PI-negative early apoptotic cells, Annexin V-positive and PI-positive late apoptotic cells, and Annexin V-negative and PI-positive necrotic cells. The proportion of viable cells in Ca9-22 cells was $54.7 \%$, and when treated with PF-543, the proportion of necrotic cells increased to $30.4 \%$ (Figure $2 \mathrm{~b}$ ). In the case of HSC-3 cells, the proportion of viable cells, necrotic cells and late apoptotic cells were $50.1 \%, 29.4 \%$ and $16.7 \%$, respectively (Figure 2b).

\section{Induction of autophagy by PF-543}

Immunofluorescence staining was performed using anti-LC3 antibody and 4',6-diamidino-2-phenylindole (DAPI) to determine the localization of LC3, the main component of autophagosomes. In untreated Ca9-22 and HSC-3 cells, a weakly diffuse cytoplasmic stained image was observed. On treatment of Ca9-22 and HSC-3 cells with $25 \mu \mathrm{M}$ PF-543 for $72 \mathrm{~h}$, a granular pattern due to strong accumulation of LC3 was observed in the cytoplasm (Figure 3a).

Upon induction of autophagy, LC3-I changes to LC3-II and accumulates in autophagosomes formed in the cytoplasm. ${ }^{16}$ On immunoblot analysis of HSC-3 cells, conversion from LC3-I to LC3II occurred $6 \mathrm{~h}$ after the start of PF-543 treatment and its level was maintained after $24 \mathrm{~h}$ (Figure 3b). LC3-Il levels of Ca9-22 and HSC-3 cells treated with PF-543 were higher than those in untreated controls (Figure 3c).

\section{Enhancement of cell death by autophagy inhibitors}

Wortmannin and 3-methyladenine (3-MA) are known inhibitors of autophagosome formation, and bafilomycin A1 inhibits the formation of autophagosomes and autolysosomes. ${ }^{20-22}$
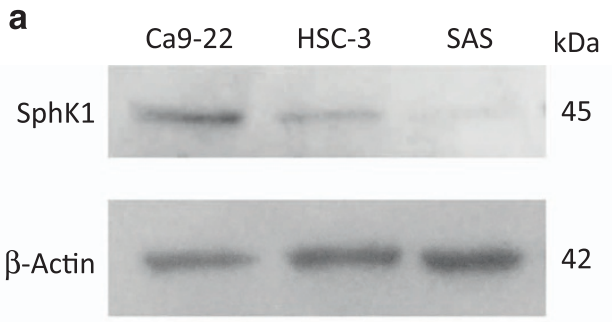

b
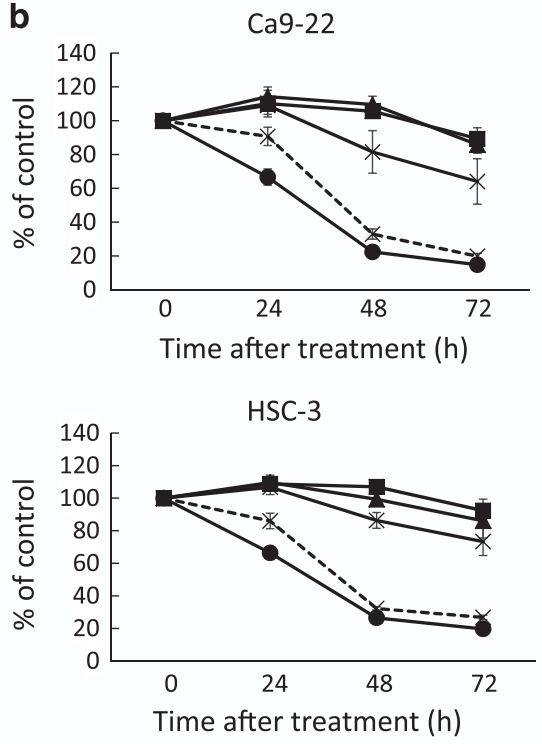

$1 \mu \mathrm{M} \smile 5 \mu \mathrm{M} \leftarrow 10 \mu \mathrm{M} \times 25 \mu \mathrm{M} \longrightarrow 50 \mu \mathrm{M}$

C

C

Ca9-22
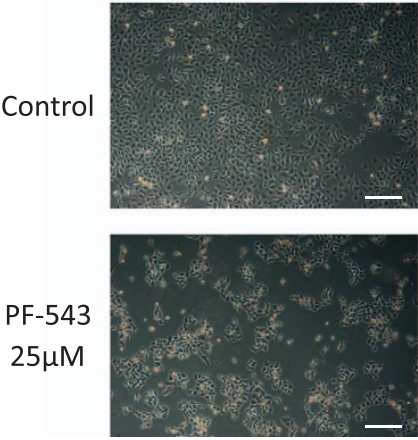

Figure 1. Inhibition of cell viability by PF-543. (a) The expression of SphK1 in Ca9-22, HSC-3 and SAS cells was examined by immunoblotting. (b) Cells $\left(2.5 \times 10^{3}\right)$ in 96 -well culture plates were cultured for $24 \mathrm{~h}$ before experiments. Ca9-22 and HSC-3 cells were treated with several concentrations of PF-543 for 24,48 and $72 \mathrm{~h}$, and cell viability was measured by MTT assay. Data are mean \pm S.D. $(n=3)$. (c) Ca9-22 and HSC-3 cells were treated with PF-543 at a concentration of $25 \mu \mathrm{M}$ for $72 \mathrm{~h}$ and the cell morphology was photographed with a phase contrast microscope. Scale bar: $200 \mu \mathrm{m}$.

Immunoblot analysis of LC3 after treatment of HSC-3 cells with PF-543 in combination with these autophagy inhibitors demonstrated that wortmannin and 3-MA reduced LC3-II expression levels (Figures $3 d$ and e). In cells treated with bafilomycin A1, high LC3-II levels were maintained (Figure $3 f$ ).

To know the effects of PF-543 on the mode of cell death, Ca9-22 and HSC-3 cells were treated with PF-543, and the populations of 
a
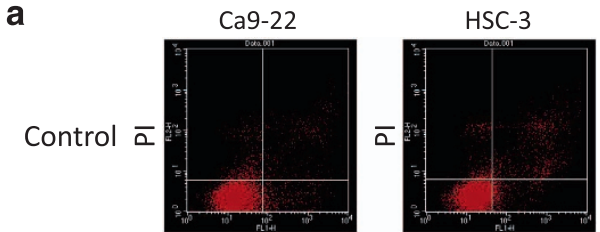

Annexin V

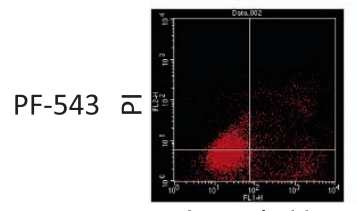

Annexin V

b

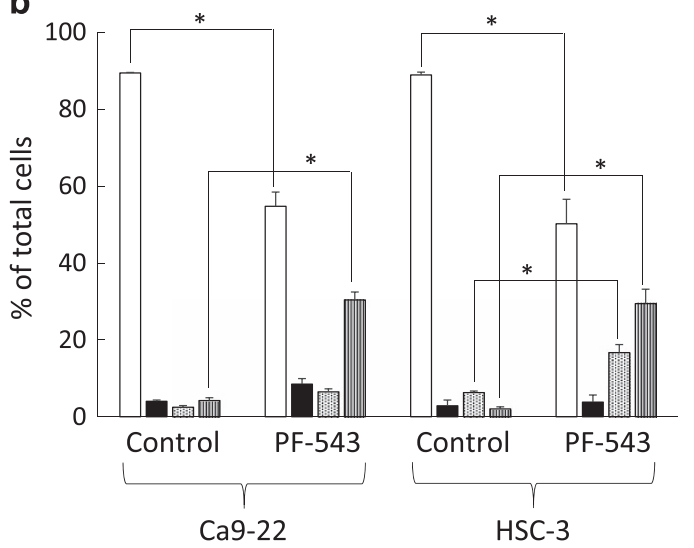

Figure 2. Induction of cell death by PF-543. (a) Cells $\left(1.0 \times 10^{5}\right)$ in 6well culture plates were cultured for $24 \mathrm{~h}$ before experiments. Ca922 and HSC -3 cells were treated with $25 \mu \mathrm{M}$ PF- 543 for $72 \mathrm{~h}$, stained with FITC-annexin $\mathrm{V}$ and $\mathrm{Pl}$, and subjected to flow cytometry. (b) Percentage of annexin V-negative and PI-negative viable cells $(\square)$, annexin V- positive and PI-negative early apoptotic cells ( $\mathbf{\square}$ ), annexin V-positive and PI-positive late apoptotic cells ( $\square$ ), and annexin V-negative and PI-positive necrotic cells $(\square)$ were determined. Data are mean \pm S.D. $(n=3) .{ }^{*} P<0.05$, unpaired two-tail $t$-test.

viable cells, apoptotic cells and necrotic cells were analyzed with a flow cytometer. Wortmannin, 3-MA, and bafilomycin A1 alone exhibited no significant inhibitory effects on the proportion of viable cells at the working concentration. The proportion of necrotic cells after treatment of Ca9-22 cells for $72 \mathrm{~h}$ with PF-543 alone was $30.4 \%$, but it increased to $45.8 \%$ with PF-543 and wortmannin (Figure 4a). Treatment with PF-543 and bafilomycin A1 resulted in a slight increase in early apoptotic cells (Figure 4b). In HSC-3 cells, after treatment with PF-543 in combination with wortmannin or 3-MA, the proportions of necrotic cells were 36.2 and $55.2 \%$ respectively, indicating that autophagy inhibitors further increased necrotic cells. A significant difference $(P<0.05)$ was observed between PF-543 alone and PF-543 with wortmannin or 3-MA (Figure 4c). When HSC-3 cells were treated with PF-543 in combination with bafilomycin A1, late apoptotic cells increased from 16.7 to $28.4 \%$. In contrast, the proportion of necrotic cells decreased from 29.4 to $11.1 \%$ (Figure $4 \mathrm{~d}$ ).

Suppression of cell death by the ROS scavenger NAC

Bioactive lipids, such as ceramides, have been reported to induce reactive oxygen species (ROS) production. ${ }^{23-25}$ The effect of a ROS scavenger, $\mathrm{N}$-acetyl-L-cysteine (NAC), on PF-543 induced cell death was investigated. HSC-3 cells were pretreated with NAC and treated with PF-543 for $72 \mathrm{~h}$, then analyzed using flow cytometry.
The proportion of necrotic cells induced by PF-543 decreased from 48.6 to $26.3 \%$. There was a significant difference between these groups (Figure 5), indicating an important role of ROS in cell death.

\section{DISCUSSION}

SphK1 is overexpressed in head and neck SCC, and positively correlates with invasion and reduced sensitivity to radiotherapy. ${ }^{3-5}$ We have demonstrated that safingol induces apoptosis and autophagy in head and neck SCC cells. ${ }^{26-28}$ Recent studies reported anti-proliferative and cytotoxic effects of PF-543 on a panel of established and primary human colorectal cancer cells. ${ }^{19}$ Based on these findings, we decided to investigate the possibility that PF-543 induced cell death and autophagy in head and neck SCC cells.

First, the expression of SphK1 in SCC cell lines derived from head and neck SCC was examined by immunoblot analysis, and expression of SphK1 was found in all tested cell lines, but its expression was diverse. Testing the ability to inhibit proliferation of SCC cells using Ca9-22 and HSC-3 cells expressing SphK1 at high levels demonstrated that cell proliferation decreased in a time- and dose-dependent manner. Morphological changes, mainly cell rounding, appeared $48 \mathrm{~h}$ after incubation with PF-543. In the first report, PF-543 did not exert strong inhibitory effects at low concentration on 1483 cells. ${ }^{13}$ However, after incubation for 4 days at a concentration of $10 \mu \mathrm{M}$, significant inhibition of proliferation of colorectal cancer cells was reported. ${ }^{19}$ As PF-543 inhibits the activity of SphK1 and reduces the level of $\mathrm{S} 1 \mathrm{P}$, which is essential for suppressing cell proliferation, long-term treatment may be necessary to exert anti-proliferative effects. When incubated for $48 \mathrm{~h}$ or more at a concentration of $25 \mu \mathrm{M}$, PF-543 appears to exhibit cytotoxic effects on head and neck SCC cells.

PF-543 was also found to induce cell death in head and neck SCC cells by flow cytometry analysis. In this analysis, the type of cell death was classified as viable cells, early apoptotic cells, late apoptotic cells or necrotic cells. The proportion of viable cells was reduced when SCC cells were treated with PF-543 for $72 \mathrm{~h}$, and necrosis was a major cause of cell death.

Consistent with the results of this study, Ju et al. ${ }^{19}$ reported that PF-543 primarily induced necrotic cell death in human colorectal cancer cells, but they did not examine the involvement of autophagy. Recently, we discovered autophagy as well as apoptosis occurred at concentrations of safingol that induce morphological changes in SCC cells. ${ }^{28}$ In the present study, we found a granular pattern of LC3 exhibiting autophagosome formation and the conversion of LC3-I to LC3-II in PF-543treated Ca9-22 and HSC-3 cells. Therefore, we concluded that PF-543 induced autophagy after treatment at concentrations that had cytotoxic effects.

Although autophagy induction by $\mathrm{PF}-543$ has not been reported to date, other SphK inhibitors, the SphK1/SphK2 inhibitor SKI-II and the SphK2 inhibitor ABC 294640, have been shown to induce autophagy. ${ }^{29,30}$ McNaughton et al. ${ }^{31}$ reported that SKI-II and ABC 294640 inhibited DNA synthesis in androgenindependent LNCaP-Al prostate cancer cells, inducing proteosomal degradation of SphK1. These effects were reproduced by inhibitors of dihydroceramide desaturase (Des 1), which is the last enzyme in the novel synthesis of ceramide to convert dihydroceramide to ceramide. As dihydroceramide accumulated by blocking Des 1, a known inducer of autophagy, ${ }^{32}$ growth arrest induced by SKI-II or ABC 294640 is considered to be mediated by SphK1 and Des 1.31 Therefore, PF-543 may demonstrate cytotoxicity by increasing the amounts of phospholipid metabolites, which induce autophagy.

Recent studies suggest that factors in the apoptotic pathway also exert regulatory activity on factors in autophagy. ${ }^{33-35}$ For 
a

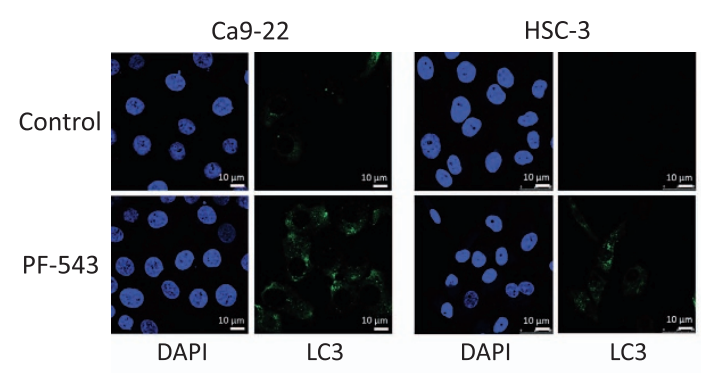

b

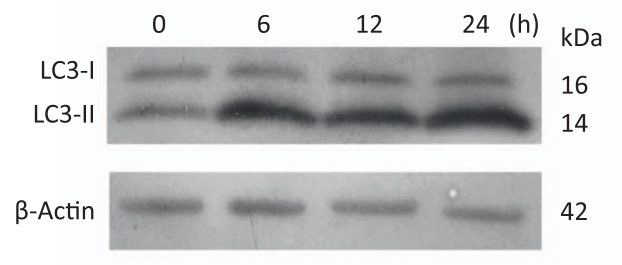

C
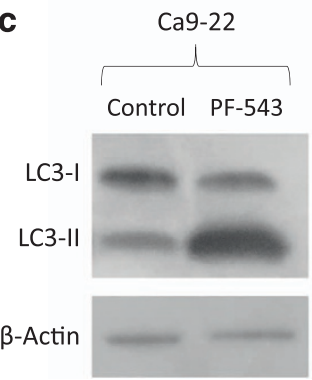

HSC-3

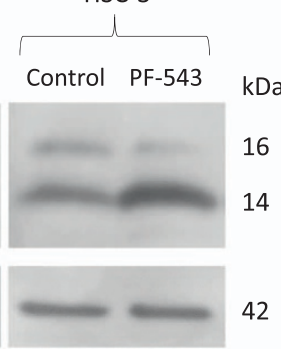

d
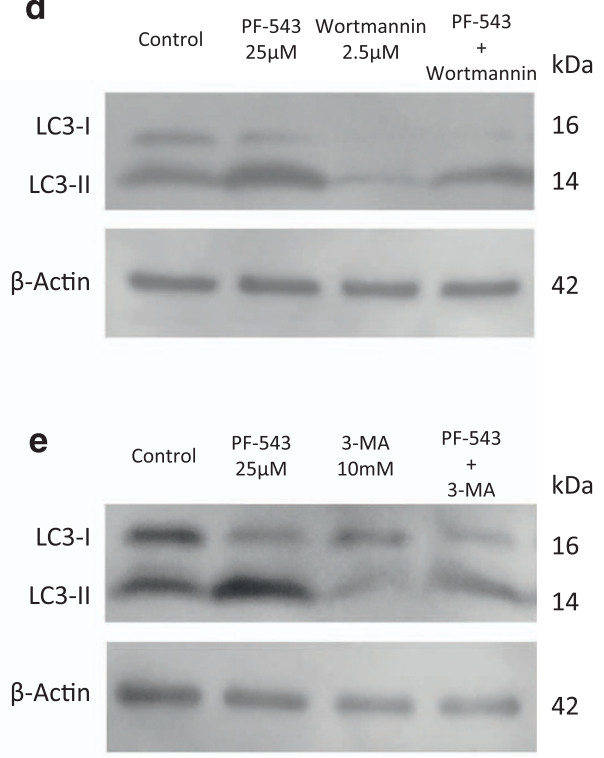

f

$\begin{array}{cccc}\text { Control } & \text { PF-543 } & \text { Bafilomycin A1 } & \text { PF-543 } \\ 25 \mu \mathrm{M} & 0.25 \mathrm{nM} & +\end{array}$ Bafilomycin $\mathrm{A} 1 \mathrm{kDa}$

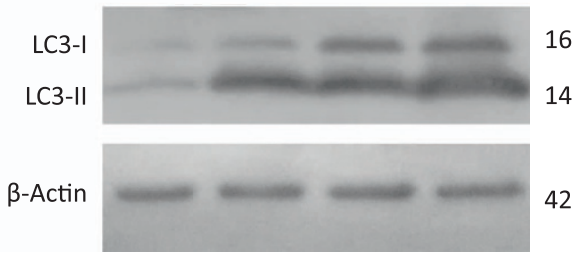

Figure 3. Induction of autophagy by PF-543. (a) Cells $\left(1.0 \times 10^{5}\right)$ in 6-well culture plates were cultured for $24 \mathrm{~h}$ before experiments. Ca9-22 and HSC -3 cells were treated with $25 \mu \mathrm{M}$ PF-543 for $72 \mathrm{~h}$ and the expression of LC 3 was examined by immunofluorescent antibody staining with anti-LC3 antibody and DAPI. (b) Expression of LC3-I and LC3-II in HSC-3 cells treated with PF-543 was examined for $24 \mathrm{~h}$ by immunoblotting. (c) Expression of LC3-I and LC3-II in Ca9-22 and HSC-3 cells treated for $72 \mathrm{~h}$ with PF-543 was examined by immunoblotting. HSC-3 cells were treated with $25 \mu \mathrm{M}$ PF-543 in combination with $2.5 \mu \mathrm{M}$ wortmannin (d), $10 \mathrm{mM}$ 3-MA (e), or $0.25 \mathrm{nM}$ bafilomycin A1 (f) for $72 \mathrm{~h}$, and LC3-I and LC3-II were detected by immunoblotting.

example, anti-apoptotic Bcl-2 family proteins that downregulate apoptosis by antagonizing the activity of pro-apoptotic proteins can downregulate autophagy. Beclin 1 interacts with antiapoptotic Bcl-2 family members, including $\mathrm{BCl}-2$ and $\mathrm{Bcl}-\mathrm{xL}$. Binding of these $\mathrm{Bcl}-2$ family proteins to Beclin 1 inhibits autophagy by altering the association of Beclin 1 and Class III phosphatidylinositol 3-kinase (PI3K) complexes. ${ }^{36}$ Ding et al. ${ }^{29}$ reported that ABC 294640-induced apoptosis in cholangiocarcinoma cells was enhanced when autophagy was inhibited by bafilomycin A1 or chloroquine. We showed that safingol induced endonuclease G-dependent apoptosis and autophagy of head and neck SCC cells, and this induced autophagy acted as a survival promoter. ${ }^{28}$ On the other hand, Goodall et al. ${ }^{37}$ reported that the deficiency of tumor suppressor gene MAP3K7 in mouse prostate cells increased sensitivity to cell death by TNF-related apoptosisinducing ligand (TRAIL). This cell death occurred primarily through necrosomes and was not apoptosis due to assembly of necrosomes in relation to the autophagy mechanism. Necrosis cell death became apoptosis if the p62-dependent mobilization of necrosomes to the autophagy mechanism was prevented. These earlier findings suggest that autophagy affects whether cells will die, as well as controls other aspects of programmed cell death such as apoptosis and necrosis.

In the present study, we found that autophagy inhibitors, wortmannin, 3-MA and bafilomycin A1 efficiently prevented the processes of autophagy. We also confirmed that these autophagy inhibitors alone do not affect the cell viability of head and neck
SCC cells. Then, flow cytometry analysis was performed by treating Ca9-22 and HSC-3 cells with PF-543 and wortmannin or 3-MA, and as a result, necrotic cells significantly increased in comparison with PF-543 alone, but early and late apoptotic cells were not significantly affected. This increase in necrotic cells by inhibiting autophagy was thought to enhance the cytotoxicity of PF-543 on head and neck SCC cells. Thus, autophagy induced by PF-543 can act to prevent necrotic cell death (Figure 6). 'Cross-talk' of autophagy and necrosis ${ }^{38}$ may be related with an increase in the necrotic cell population due to inhibition of autophagy by wortmannin and 3-MA. In the case of bafilomycin A1, the change in necrosis was minimal and the apoptotic cells increased. Cell death patterns of Ca9-22 and HSC-3 cells may be switched from necrosis to apoptosis by inhibition of autophagy with bafilomycin A1.

Necrosis mediators are excess cytoplasmic $\mathrm{Ca}^{2+}$ and levels of ROS. ${ }^{39}$ Previous studies have demonstrated that ROS production can mediate apoptosis and/or autophagy induction in several types of cancer cells. ${ }^{23}$ Ling et al. ${ }^{24}$ reported an important role of ROS in necrosis of safingol-treated cells. We also reported ROS production by safingol in head and neck SCC cells. ${ }^{25}$ In this study, we found that the removal of ROS by $\mathrm{N}$-acetyl-L-cysteine (NAC) prevented the production of necrotic cells by PF-543. Therefore, it is likely that ROS generated by PF-543 is a mediator of PF-543induced cell death and autophagy.

In conclusion, our results demonstrated that PF-543 induced apoptosis, necrosis and autophagy in human head and neck SCC 

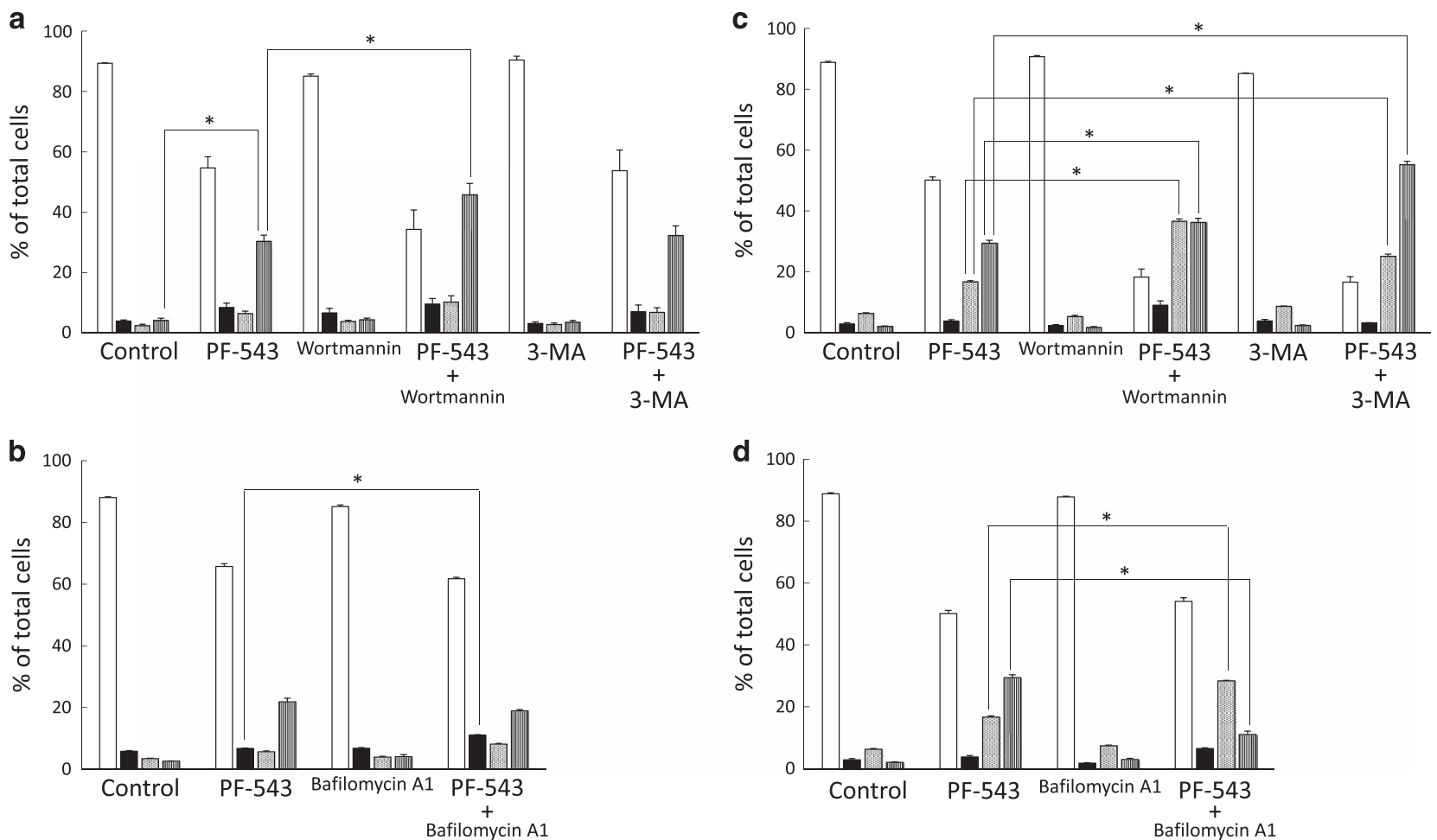

Figure 4. Enhancement of cell death by autophagy inhibitor. Cells $\left(1.0 \times 10^{5}\right)$ in 6-well culture plates were cultured for $24 \mathrm{~h}$ before experiments. Ca9-22 cells were treated for $72 \mathrm{~h}$ with PF-543 and wortmannin (a), 3-MA (a), or bafilomycin A1 (b), stained with FITC-annexin V and PI, and subjected to flow cytometry. HSC-3 cells were treated with PF-543 in combination with wortmannin (c), 3-MA (c), or bafilomycin A1 (d). The percentage of viable cells $(\square)$, early apoptotic cells $(\square)$, late apoptotic cells $(\square)$, and necrotic cells $(\square)$ was determined. Data are mean \pm S.D. $(n=3)$. ${ }^{*} P<0.05$, unpaired two-tail $t$-test.

cells, and that induced autophagy antagonized both necrosis and apoptosis.

\section{MATERIALS AND METHODS}

Cells

The human oral SCC cell line SAS and HSC-3 cells were obtained from the RIKEN BRC CELL BANK (Tsukuba, Japan), and Ca9-22 cells were from the Japanese Collection of Research Bioresources (Tokyo, Japan). Cells were cultured in Dulbecco's modified Eagle's medium supplemented with $5 \%$ fetal bovine serum, $4 \mathrm{mM} \mathrm{L-glutamine,} 100 \mu \mathrm{g} / \mathrm{ml}$ penicillin and $100 \mu \mathrm{g} / \mathrm{ml}$ streptomycin, and then grown in an incubator at $37{ }^{\circ} \mathrm{C}$ in a humidified atmosphere with $5 \% \mathrm{CO}_{2}$.

\section{Reagents}

Sphingosine kinase 1 inhibitor (PF-543) was obtained from Merck KGaA (Darmstadt, Germany) and a stock solution was made in dimetyl sulphoxide (DMSO). Wortmannin, 3-MA, bafilomycin A1, and MTT were obtained from Sigma (St. Louis, MO, USA). NAC was obtained from Wako (Osaka, Japan).

\section{MTT assay}

Cells grown in 96-well culture plates were treated with PF-543. Thereafter, $10 \mu \mathrm{l}$ of $5 \mathrm{mg} / \mathrm{ml} \mathrm{MTT}$ solution was added to each well with $100 \mu \mathrm{l}$ of medium and cells were incubated at $37^{\circ} \mathrm{C}$ for $4 \mathrm{~h}$. After the addition of $100 \mu \mathrm{l}$ of $0.04 \mathrm{~N} \mathrm{HCl}$ in isopropanol, the plates were mixed thoroughly to dissolve the dark blue crystals and remained at room temperature overnight. The plates were read on a Benchmark Plus microplate spectrophotometer (Bio-Rad Laboratories, Hercules, CA, USA) with a reference wavelength of $630 \mathrm{~nm}$ and a test wavelength of $570 \mathrm{~nm}$. Background absorbance at $630 \mathrm{~nm}$ was subtracted from the $570 \mathrm{~nm}$ reading.
Flow cytometry analysis

FITC-annexin V and PI staining was performed using Vybrant Apoptosis Assay Kit \#3 (Life Technologies, Carlsbad, CA, USA) following the manufacturer's directions. After being treated, floating cells were harvested with medium and attached cells were dissociated with EDTA-trypsin solution. Cells were collected by centrifugation at $1000 \mathrm{r}$. p.m. for $5 \mathrm{~min}$. Cells were centrifuged and washed twice with phosphate-buffered saline (PBS), and the pellets were suspended in $100 \mu \mathrm{l}$ binding buffer containing $10 \mathrm{mM}$ HEPES, $140 \mathrm{mM} \mathrm{NaCl}$ and $2.5 \mathrm{mM} \mathrm{CaCl}(\mathrm{pH} 7.4)$, and incubated with $5 \mu \mathrm{l}$ of FITC-annexin $\mathrm{V}$ and $1 \mu \mathrm{l}$ of $100 \mu \mathrm{g} / \mathrm{ml} \mathrm{PI}$ solution for $15 \mathrm{~min}$ at room temperature. Thereafter, $400 \mu \mathrm{l}$ of binding buffer was added, mixed gently, and kept on ice. Stained cells were analyzed by FACSCalibur (Becton Dickinson, Mountain View, CA, USA). Data were analyzed by Cell Quest software (Becton Dickinson).

\section{Immunoblot analysis}

To detect proteins, cells were washed in PBS and lysed in a buffer containing $20 \mathrm{mM}$ Tris- $\mathrm{HCl}$ (pH 7.4), 0.1\% SDS, 1\% Triton X-100, $1 \%$ sodium deoxycholate and protease inhibitor cocktail. After sonication on ice and subsequent centrifugation at $15000 \times g$ for $10 \mathrm{~min}$ at $4{ }^{\circ} \mathrm{C}$, the supernatant was collected and the protein concentration was determined using a Protein Assay Kit (Bio-Rad, Hercules, CA, USA). A protein sample (20 $\mu \mathrm{g})$ was electrophoresed through a polyacrylamide gel and transferred to a PVDF membrane (Millipore, Bedford, MA, USA) by electroblotting. The membrane was probed with antibodies and antibody binding was detected using an enhanced chemiluminescence (ECL) kit (GE Healthcare, Amersham, Buckinghamshire, UK) according to the manufacturer's instructions. The antibodies used were as follows: rabbit polyclonal antibodies against SphK1 (Cell Signaling Technology, Beverly, MA, USA), mouse monoclonal antibodies against LC3 and $\beta$-actin (Medical \& Biological Laboratories, Nagoya, Japan), and horseradish peroxidase-conjugated secondary antibodies (Cell Signaling Technology). 


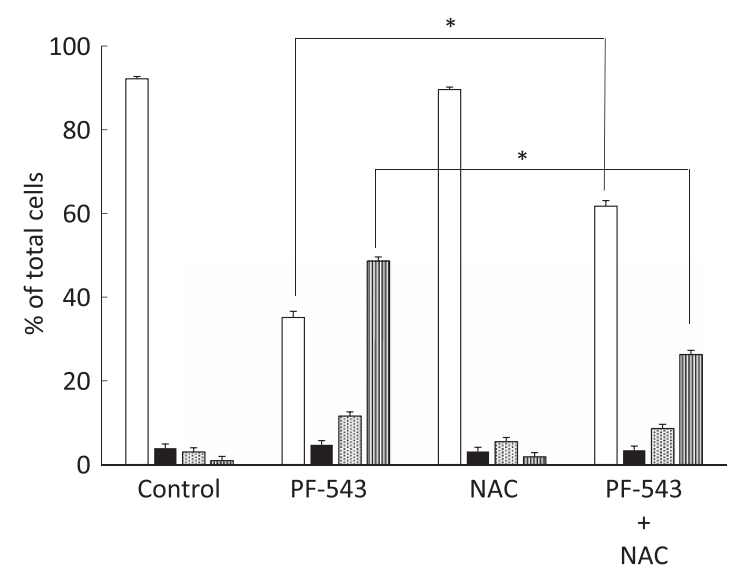

Figure 5. Suppression of cell death by the ROS scavenger, NAC. Cells $\left(1.0 \times 10^{5}\right)$ in 6 -well culture plates were cultured for $24 \mathrm{~h}$ before experiments. HSC-3 cells were pretreated with NAC for $2 \mathrm{~h}$, then treated with PF-543 in the presence of NAC for $72 \mathrm{~h}$. They were stained with FITC-annexin V and PI, and then subjected to flow cytometry. The percentage of viable cells $(\square)$, early apoptotic cells $(\square)$, late apoptotic cells $(\square)$ and necrotic cells $(\square)$ was determined. Data are mean \pm S.D. $(n=3) .{ }^{*} P<0.05$, unpaired two-tail $t$-test.

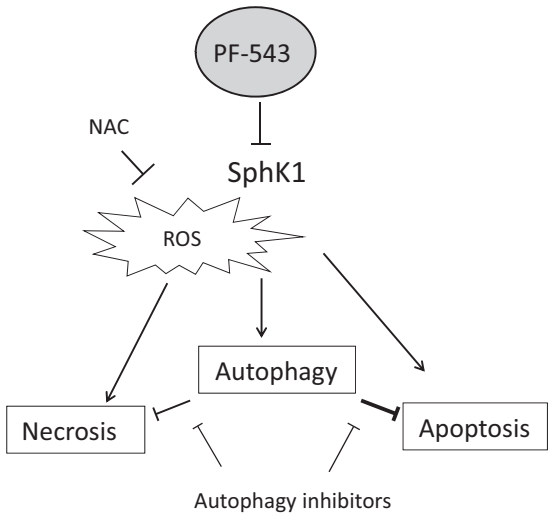

Figure 6. Schematic representation of the effects of PF-543 on head and neck SCC cells. PF-543 inhibits the activity of SphK1 in head and neck SCC cells, decreases S1P and induces necrosis and apoptotic cell death, as well as autophagy. Autophagy inhibitors can block the inhibitory effects of autophagy on necrosis and apoptotic pathways, and can enhance PF-543-induced cytotoxicity. ROS is a mediator of cell death induced by PF- 543 .

Confocal laser microscopic analysis

After being treated, cells were fixed in $4 \%$ paraformaldehyde phosphate buffer solution (Wako) and incubated with an antibody against LC3 diluted 1:500 for $1 \mathrm{~h}$ at room temperature. After washing, the cells were incubated with an Alexa Fluor 488 goat anti-mouse IgG antibody (Life Technologies, Carlsbad, CA, USA) diluted 1:500 in PBS for $1 \mathrm{~h}$. After washing, coverslips were mounted onto microslides using a ProLong Gold Antifade Reagent with DAPI (Life Technologies Corporation). The slides were analyzed with the confocal laser-scanning microscope Leica TCS SP8 (Leica Microsystems, Mannheim, Germany).

\section{Statistical analyses}

Statistical analyses were performed using the Student's $t$-test with Microsoft Excel (Microsoft, Redmond, WA, USA). Results were expressed as the mean \pm S.D. Differences were considered significant at $P<0.05$.

\section{ACKNOWLEDGEMENTS}

This work was supported in part by a Grant-in Aid for Scientific Research from the Japan Society for the Promotion of Science (No.15K11243).

\section{COMPETING INTERESTS}

The authors declare no conflict of interest.

\section{PUBLISHER'S NOTE}

Springer Nature remains neutral with regard to jurisdictional claims in published maps and institutional affiliations.

\section{REFERENCES}

1 Kawamori T, Kaneshiro T, Okumura M, Maalouf S, Uflacker A, Bielawski J et al. Role for sphingosine kinase 1 in colon carcinogenesis. FASEB J 2009; 23: 405-414.

2 Spiegel S, Milstien S. Sphingosine-1-phosphate: an enigmatic signalling lipid. Nat Rev Mol Cell Biol 2003; 4: 397-407.

3 Tamashiro PM, Furuya H, Shimizu Y, lino K, Kawamori T. The impact of sphingosine kinase-1 in head and neck cancer. Biomolecules 2013; 3: 481-513.

4 Pyne NJ, Pyne S. Sphingosine 1-phosphate and cancer. Nat Rev Cancer 2010; 10: 489-503.

5 Nema R, Vishwakarma S, Agarwal R, Panday RK, Kumar A. Emerging role of sphingosine-1-phosphate signaling in head and neck squamous cell carcinoma. Onco Targets Ther 2016; 9: 3269-3280.

6 Dickson MA, Carvajal RD, Merrill Jr AH, Gonen M, Cane LM, Schwartz GK. A phase I clinical trial of safingol in combination with cisplatin in advanced solid tumors. Clin Cancer Res 2011; 17: 2484-2492.

7 Yatomi Y, Ruan F, Megidish T, Toyokuni T, Hakomori S, Igarashi YN. $\mathrm{N}$-dimethylsphingosine inhibition of sphingosine kinase and sphingosine 1-phosphate activity in human platelets. Biochemistry 1996; 35: 626-633.

8 Edsall LC, Van Brocklyn JR, Cuvillier O, Kleuser B, Spiegel SN. $\mathrm{N}$-Dimethylsphingosine is a potent competitive inhibitor of sphingosine kinase but not of protein kinase C: modulation of cellular levels of sphingosine 1-phosphate and ceramide. Biochemistry 1998; 37: 12892-12898.

9 Olivera A, Kohama T, Tu Z, Milstien S, Spiegel S. Purification and characterization of rat kidney sphingosine kinase. J Biol Chem 1998; 273: 12576-12583.

10 Coward J, Ambrosini G, Musi E, Truman JP, Haimovitz-Friedman A, Allegood JC et al. Safingol (L-threo-sphinganine) induces autophagy in solid tumor cells through inhibition of PKC and the PI3-kinase pathway. Autophagy 2009; 5: 184-193.

11 French KJ, Schrecengost RS, Lee BD, Zhuang Y, Smith SN, Eberly JL et al. Discovery and evaluation of inhibitors of human sphingosine kinase. Cancer Res 2003; 63: 5962-5969.

12 Brinkmann V, Davis MD, Heise CE, Albert R, Cottens S, Hof R et al. The immune modulator FTY720 targets sphingosine 1-phosphate receptors. J Biol Chem 2002; 277: 21453-21457.

13 Schnute ME, McReynolds MD, Kasten T, Yates M, Jerome G, Rains JW et al. Modulation of cellular S1P levels with a novel, potent and specific inhibitor of sphingosine kinase-1. Biochem J 2012; 444: 79-88.

14 Mizushima N, Komatsu M. Autophagy: renovation of cells and tissues. Cell 2011; 147: 728-741.

15 Liang XH, Jackson S, Seaman M, Brown K, Kempkes B, Hibshoosh H et al. Induction of autophagy and inhibition of tumorigenesis by beclin 1. Nature 1999; 402: 672-676.

16 Tanida I, Ueno T, Kominami E. Human light chain 3/MAP1LC3B is cleaved at its carboxyl-terminal Met121 to expose Gly120 for lipidation and targeting to autophagosomal membranes. J Biol Chem 2004; 279: 47704-47710.

17 Dalby KN, Tekedereli I, Lopez-Berestein G, Ozpolat B. Targeting the prodeath and prosurvival functions of autophagy as novel therapeutic strategies in cancer. Autophagy 2010; 6: 322-329.

18 Kondo Y, Kanzawa T, Sawaya R, Kondo S. The role of autophagy in cancer development and response to therapy. Nat Rev Cancer 2005; 5: 726-734.

19 Ju T, Gao D, Fang ZY. Targeting colorectal cancer cells by a novel sphingosine kinase 1 inhibitor PF-543. Biochem Biophys Res Commun 2016; 470: 728-734.

20 Moon JH, Lee JH, Lee YJ, Park SY. Hinokitiol protects primary neuron cells against prion peptide-induced toxicity via autophagy flux regulated by hypoxia inducing factor-1. Oncotarget 2016; 7: 29944-29957.

21 Seglen PO, Gordon PB. 3-Methyladenine: specific inhibitor of autophagic/lysosomal protein degradation in isolated rat hepatocytes. Proc Natl Acad Sci USA 1982; 79: 1889-1892. 
22 Yamamoto A, Tagawa Y, Yoshimori T, Moriyama Y, Masaki R, Tashiro Y. Bafilomycin A1 prevents maturation of autophagic vacuoles by inhibiting fusion between autophagosomes and lysosomes in rat hepatoma cell line, H-4-II-E cells. Cell Struct Funct 1998; 23: 33-42.

23 Sachs CW, Safa AR, Harrison SD, Fine RL. Partial inhibition of multidrug resistance by safingol is independent of modulation of P-glycoprotein substrate activities and correlated with inhibition of protein kinase C. J Biol Chem 1995; 270: 26639-26648.

24 Ling LU, Tan KB, Lin H, Chiu GN. The role of reactive oxygen species and autophagy in safingol-induced cell death. Cell Death Dis 2011; 2: e129.

25 Hamada M, Wakabayashi K, Masui A, Iwai S, Imai T, Yura Y. Involvement of hydrogen peroxide in safingol-induced endonuclease G-mediated apoptosis of squamous cell carcinoma cells. Int J Mol Sci 2014; 15: 2660-2671.

26 Hamada M, Sumi T, Iwai S, Nakazawa M, Yura Y. Induction of endonuclease G-mediated apopotosis in human oral squamous cell carcinoma cells by protein kinase C inhibitor safingol. Apoptosis 2006; 11: 47-56.

27 Noda T, Iwai S, Hamada M, Fujita Y, Yura Y. Induction of apoptosis of detached oral squamous cell carcinoma cells by safingol. Possible role of Bim, focal adhesion kinase and endonuclease G. Apoptosis 2009; 14: 287-297.

28 Masui A, Hamada M, Kameyama H, Wakabayashi K, Takasu A, Imai T et al. Autophagy as a survival mechanism for squamous cell carcinoma cells in endonuclease G-mediated apoptosis. PLoS One 2016; 11: e0162786.

29 Ding X, Chaiteerakij R, Moser CD, Shaleh H, Boakye J, Chen G et al. Antitumor effect of the novel sphingosine kinase 2 inhibitor $A B C 294640$ is enhanced by inhibition of autophagy and by sorafenib in human cholangiocarcinoma cells. Oncotarget 2016; 7: 20080-20092.

30 Beljanski V, Knaak C, Smith CD. A novel sphingosine kinase inhibitor induces autophagy in tumor cells. J Pharmacol Exp Ther 2010; 333: 454-464.

31 McNaughton M, Pitman M, Pitson SM, Pyne NJ, Pyne S. Proteasomal degradation of sphingosine kinase 1 and inhibition of dihydroceramide desaturase by the sphingosine kinase inhibitors, SKi or ABC294640, induces growth arrest in androgen-independent LNCaP-Al prostate cancer cells. Oncotarget 2016; 7: 16663-16675.
32 Cingolani F, Casasampere M, Sanllehi P, Casas J, Bujons J, Fabrias G. Inhibition of dihydroceramide desaturase activity by the sphingosine kinase inhibitor SKI II. J Lipid Res 2014; 55: 1711-1720.

33 Ryter SW, Mizumura K, Choi AM. The impact of autophagy on cell death modalities. Int J Cell Biol 2014; 2014: 502676.

34 Giansanti V, Torriglia A, Scovassi Al. Conversation between apoptosis and autophagy: 'Is it your turn or mine?'. Apoptosis 2011; 16: 321-333.

35 Maiuri MC, Zalckvar E, Kimchi A, Kroemer G. Self-eating and self-killing: crosstalk between autophagy and apoptosis. Nat Rev Mol Cell Biol 2007; 8: $741-752$.

36 Pattingre S, Tassa A, Qu X, Garuti R, Liang XH, Mizushima N et al. Bcl-2 antiapoptotic proteins inhibit Beclin 1-dependent autophagy. Cell 2005; 122: 927-939.

37 Goodall ML, Fitzwalter BE, Zahedi S, Wu M, Rodriguez D, Mulcahy-Levy JM et al. The autophagy machinery controls cell death switching between apoptosis and necroptosis. Dev Cell 2016; 37: 337-349.

38 Mathew R, Karantza-Wadsworth V, White E. Role of autophagy in cancer. Nat Rev Cancer 2007; 7: 961-967.

39 Vaseva AV, Marchenko ND, Ji K, Tsirka SE, Holzmann S, Moll UM. p53 opens the mitochondrial permeability transition pore to trigger necrosis. Cell 2012; 149: 1536-1548.

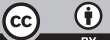

This work is licensed under a Creative Commons Attribution 4.0 International License. The images or other third party material in this article are included in the article's Creative Commons license, unless indicated otherwise in the credit line; if the material is not included under the Creative Commons license, users will need to obtain permission from the license holder to reproduce the material. To view a copy of this license, visit http://creativecommons.org/licenses/ by/4.0/

(c) The Author(s) 2017 